\title{
A One-Team approach to crisis management: a hospital success story during the COVID-19 pandemic
}

\author{
Tracy H. Porter ${ }^{1}$, Cheryl Rathert ${ }^{2}$, Sabry Ayad ${ }^{3}$, Nicholas Messina ${ }^{1}$ \\ ${ }^{1}$ Department of Management, Cleveland State University, Cleveland, OH, USA; ${ }^{2}$ Department of Public Health, St. Louis University, St. Louis, MO, \\ USA; ${ }^{3}$ Department of Anesthesiology, Cleveland Clinic, Cleveland, OH, USA \\ Contributions: (I) Conception and design: TH Porter, C Rathert, S Ayad; (II) Administrative support: N Messina; (III) Provision of study materials or \\ patients: TH Porter, C Rathert, S Ayad; (IV) Collection and assembly of data: TH Porter, C Rathert, S Ayad; (V) Data analysis and interpretation: \\ TH Porter, C Rathert, S Ayad; (VI) Manuscript writing: All authors; (VII) Final approval of manuscript: All authors. \\ Correspondence to: Tracy H. Porter. Cleveland State University, 2121 Euclid Avenue, BU 428, Cleveland, OH 44115, USA. Email: t.h.porter@csuohio.edu.
}

\begin{abstract}
In the later months of 2019, coronavirus disease of 2019 (COVID-19) began to spread across the globe. The pandemic quickly became a challenge for healthcare facilities to respond to and hospitals were expected to lose billions. Subsequently, many hospitals implemented mandatory furloughs, layoffs or pay cuts amongst their clinical staffs. Previous research has demonstrated it is important for organizational members to pull together and act as a team during a crisis situation. A team approach offers a number of organizational benefits however; most of the literature on teamwork is focused at the micro level (e.g., unit level) and does not address the importance of an organizational level team. We propose the importance of creating an organizational level team (e.g., one, which spans throughout the organization) as being key to successfully mitigating organizational crises. We offer an applied social identity approach as a theoretical lens to understand this phenomenon. We offer insight into one hospital, which dealt with the COVID-19 pandemic based on an organizational wide team. We explain the steps the Cleveland Clinic took in preparation for and during the pandemic. These steps allowed the Clinic to avoid many of the negative consequences other hospitals suffered, such layoffs, furloughs, and potential long-term organizational workforce problems.
\end{abstract}

Keywords: Coronavirus disease of 2019 (COVID-19); Cleveland Clinic; pandemic; leadership; One-Team

Received: 21 October 2020; Accepted: 05 February 2021; Published: 25 June 2021.

doi: $10.21037 /$ jhmhp-21-9

View this article at: http://dx.doi.org/10.21037/jhmhp-21-9

\section{Introduction}

In November/December 2019 the coronavirus disease of 2019 (COVID-19) was identified and began to spread. The virus spread quickly across the globe and began to challenge governments and healthcare facilities to respond appropriately (1). On March 11, 2020 the World Health Organization (WHO) formally declared COVID-19 a pandemic. Normally, health care organizations (HCOs) are prepared for typical disease levels in their populations (1). However, COVID-19 tested traditional epidemic protocols as the disease surpassed the scope of previous pandemics.

U.S. hospitals were expected to lose $\$ 323.1$ billion in 2020 due to the COVID-19 pandemic, according to a report from the American Hospital Association (1). The total includes $\$ 120.5$ billion in financial losses from July through December, as well as $\$ 202.6$ billion in losses that were projected between March and June. The losses are largely due to a lower patient volume after canceling elective procedures (2). Although Congress allocated \$175 billion to help hospitals offset some of the revenue losses, hospital leaders have said it is not enough (2).

To address the financial fallout from COVID-19, hospitals across the nation implemented mandatory furloughs, layoffs or pay cuts amongst their clinical staffs (3). Nearly 270 hospitals and health systems enacted such cost cutting strategies with potential long-term consequences. Health care workers who have been laid off tend to have 
decreased feelings of job security, increased anxiety levels, and increased diagnoses of depression $(4,5)$. Laying off health care workers will also have a negative impact on the health of the community, as there will be less access to medical care (6). Therefore, it is imperative healthcare system leaders recognize the costs to health care workers who find themselves unemployed and seek creative ways to avoid such decisions.

One key to success during any organizational crisis is for all caregivers to pull together and act as a team (7). A team approach to crisis management brings benefits for caregivers such as increased positive affect, crisis resilience, creativity, and agreement on important decisions $(7,8)$. However, most of the literature on teamwork is focused at the micro level (e.g., unit level) and does not address the importance of an organizational level team. The rational for the focus on the micro level is an important consideration for future research but, could be as simplistic as size (7). perspective could be based on a number of reasons. In addition, healthcare systems might examine the methods implemented by other hospitals and especially those, which successfully mitigated the pandemic.

We therefore propose the importance of creating an organizational level team (e.g., one, which spans throughout the organization) as being key to successfully mitigating organizational crises. An organizational level team would offer the organization consistency with regard to messaging, processes, evaluation criteria, and offers the "team" level benefits noted earlier to the organization as a whole. Certainly, this would need to be empirically evaluated. We offer an applied social identity approach as a theoretical lens to understand this phenomenon (9). Through the following case presentation, we offer insight into one such organization, which dealt with the COVID-19 pandemic based on an organizational wide team. We explain the steps the Cleveland Clinic took in preparation for and during the pandemic. These steps allowed the health system to avoid many of the negative consequences other hospitals suffered, such as layoffs, furloughs, and potential long-term organizational workforce problems (10).

\section{Case presentation}

In January 2020, the Cleveland Clinic system leadership recognized the impending challenges approaching the United States as the COVID-19 pandemic began to surge. Leadership began to organize resources and ready the organization based on the knowledge of how the pandemic impacted hospitals elsewhere. The following discussion demonstrates the key steps and action areas addressed by this HCO to proactively prepare for the pandemic. We build on the work of Paavola [2020] who noted the steps the Cleveland Clinic took to maximize the potential in its workforce. We interviewed Dr. Mark Taylor, Chair of Surgical Operations for the Cleveland Clinic, who offered first-hand accounts of his experiences during the pandemic and was a key architect of the Cleveland Clinic COVID-19 response.

\section{Engage key stakeholders}

According to Dr. Taylor, the Cleveland Clinic successfully responded to the pandemic for a number of reasons. First, the health system deployed excess caregivers to assist other hospital surges in the early stages of the pandemic. Frontline providers were able to witness what others were doing. Leaders made a number of strategic moves proactively and were committed to transparency with the full organization. They developed an Incident Command Center (ICC) to serve as the central hub for information and delegation. The ICC developed several working groups at both the system and sub-system levels. System-wide groups focused on communication and collaboration while the sub-system groups focused on more specific localized issues and challenges.

\section{Physical space/bed capacity}

Next, the ICC groups assessed the availability of beds throughout the system and examined the potential of converting some beds to additional ICU capacity. Cleveland Clinic converted the main atrium of its Health Education Campus into a 327-bed surge hospital to be used for lowacuity COVID-19 patients. In addition to repurposing non-medical spaces for patient beds, the State of Ohio temporarily canceled elective surgeries to allow additional bed space. Many HCOs responded to this mandate by laying off or furloughing caregivers assigned to these units. However, the health system redeployed the caregivers associated with these units to the pandemic front lines rather than laying them off.

\section{Re-deployment of workforce}

Re-deployment of its clinical workforce to the front lines from other areas of the system required some planning, 
training, and understanding. New protocols needed to be developed quickly (within weeks) and training programs established. Since non-essential units were shut down, many clinical caregivers were available to assist with COVID-19. Each of these individuals was assigned to a "team group" to support the front line. Though these caregivers had the basic medical knowledge and skills needed to care for COVID-19 patients, many needed additional training to address the unique needs of COVID-19 patients. The hospital first assessed the learning needs for the redeployed caregivers and then began to develop "crash courses" to get them prepared. These courses focused on areas such as appropriate personal protective equipment (PPE) use, isolation precaution, ventilator use, and medications. The courses were offered online so that caregivers could complete them remotely.

\section{Equipment challenges}

Caregivers all over the nation expressed concern about shortages of PPE. Sometimes this fear led to hoarding of equipment, or personally purchasing inferior equipment. To mitigate these challenges, Cleveland Clinic took an accounting of all key equipment needed for COVID-19 patients. An online dashboard was established on the organization's intranet to show real-time information. All caregivers were able to access the dashboard to see the numbers and location of PPE, ventilators, and other materials. The goals of this step were to be fully transparent with caregivers in order to mitigate possible hoarding, to show caregivers there were adequate resources, and to keep them from purchasing materials elsewhere. Dr. Taylor felt the dashboards were very successful and assured caregivers the health system cared about their wellbeing, and did not want them to worry about resources. Dr. Taylor also felt this approach worked because Cleveland Clinic had a longstanding culture of transparency, and therefore they trusted the information was correct.

\section{Communication strategy}

From the beginning of the pandemic Cleveland Clinic leadership incorporated transparent communication into every step of the response plan. First, they developed content on COVID-19 policies, procedures, training resources, and webinars. Next, they established daily organization-wide webinars led by top executives, which anyone in the hospital system could join. During these calls, leaders shared information, discussed challenges, brainstormed solutions, and clarified misinformation. After the updates, there was an "open mic" portion of the call where caregivers were able to ask questions, share concerns, or simply gain clarity on COVID-19 topics. According to Dr. Taylor, caregivers would often share stories of hope, inspiration, and encouragement. "Within a high stress environment such stories offered caregivers a sense of pride, motivation, and camaraderie," Dr. Taylor stated.

\section{Discussion}

\section{A One-Team approach}

Teamwork is considered the number one global workforce development trend (11). Working collaboratively has become an imperative for contemporary organizations and "collaboration is taking over the workplace" (12). Effective teams have demonstrated a number of organizational benefits including, outcomes that are greater than the sum of individual contributions $(13,14)$. This includes improved decisionmaking, increased commitment, increased collaboration, and improved development opportunities (15). As teamoriented work increases, organizations are "implementing networks of teams, whereby projects are assigned to groups of individuals who work interdependently, employ high levels of empowerment, communication freely" (16). The One-Team (organizational level team) approach is somewhat unique given that most of the teamwork literature focuses at the unit level.

Central to the Cleveland Clinic's mission is the culture of acting as One-Team, even though it has 18 locations across the globe. Dr. Taylor explains that the "One-Team approach is built on full transparency of information regardless of employee status." This approach is a long-standing pillar within the Cleveland Clinic. Thus, a level of trust between caregivers and the system leadership allowed the organization to pivot quickly when the pandemic became a global crisis. As other hospital systems seek ways to ensure they can adapt to disruptive external environmental changes, such as pandemics, they might consider the OneTeam approach and examine the Cleveland Clinic culture.

The redeployment of clinical staff during the pandemic brought a number of benefits to the Cleveland Clinic. The redeployment allowed the Cleveland Clinic to avoid having to implement furloughs, layoffs, or pay cuts among clinical staff. In addition, the training protocols employed as part of the redeployment process offered their clinical staff new skills and knowledge, which would be of value in the 
prevention and treatment of future pandemics.

\section{Applied social identity approach to organizational crisis}

One theoretical lens which applies to the Cleveland Clinic One-Team culture is the applied social identity approach (ASIA) (9), which sprang from social identity theory (SIT) (17) and self-categorization theory (SCT) (18); two related but distinct social psychological theories. SIT focuses on intergroup relationships and SCT focuses on the role of social categorization processes in group formation and coordinated action (9). The focus of this framework is to understand how social behavior is influenced beyond the individual's viewpoint but is also influenced by the individual's sense of being a member of a larger social group (9). The ASIA has been applied to a wide variety of fields and continues to be very effective.

The ASIA approach for offers five strategies HCOs may consider. First, groups and social identities form the basis for social behaviors (17). In fact, when individuals define themselves in terms of their social identity, they will make important decisions to ensure the group is successful (9). Second, self-categorization (how one views oneself) offers a reason for group membership (19). For example, selfcategorization impacts the way an individual dresses, speaks (jargon), and their interests. Third, the real power of the group is found through working with social identities and not against them (9). Specifically, the shared identities foster collaborative environments. Fourth, social identities need to be "made to matter" (9). Which means, the groups procedures, rules, and formal procedures need to be used as a means of promoting well-being and constructive engagement (20). Finally, psychological intervention is political because it involves social identity management (9).

The Cleveland Clinic culture is one very much built on the concept of "we" as opposed to "I" where caregivers flourish when they understand and work as a team based on "we". According to Dr. Taylor, the inherent autonomy of some medical disciplines (e.g., surgeons) makes this shift difficult for some individuals. In addition, some medical disciplines work in satellite locations or may not interact with other departments on a regular basis. Such arrangements further isolate those in specific disciplines. But because Cleveland Clinic had been focusing for years on its "we" identity, the quick shift necessary during the COVID-19 surge was a lot more manageable. The lesson here is for hospital's to start building their One-Team cultures now.

\section{Conclusions}

The COVID-19 pandemic placed a tremendous burden on the global health care community and many medical systems still struggle with the financial impact. Cleveland Clinic, however, seemed to avoid many of the difficult outcomes other systems experienced (e.g., layoffs, furloughs). The key to these successes lies in Cleveland Clinic's unique One-Team organizational culture. Other systems might learn from the Cleveland Clinic approach, disruptive environmental events are inevitable. This article offers insight into why Cleveland Clinic might have been successful and how other health care systems might develop a One-Team culture themselves.

\section{Acknowledgments}

The authors would like to acknowledge Dr. Mark Taylor, Chair of Surgical Operations for the Cleveland Clinic, for his gracious contribution to this article.

Funding: None.

\section{Footnote}

Provenance and Peer Review: This article was commissioned by the Guest Editors (Erick Guerrero and Jemima A. Frimpong) for the series "Organizational Approaches to Implement Rapid Change in Hospitals to Respond to Public Health Emergencies" published in Fournal of Hospital Management and Health Policy. The article has undergone external peer review.

Conflict of Interest: The authors have completed the ICMJE uniform disclosure forms (available at http://dx.doi. org/10.21037/jhmhp-21-9). The series "Organizational Approaches to Implement Rapid Change in Hospitals to Respond to Public Health Emergencies" was commissioned by the editorial office without any funding or sponsorship. The authors have no other conflicts of interest to declare.

Ethical Statement: The authors are accountable for all aspects of the work in ensuring that questions related to the accuracy or integrity of any part of the work are appropriately investigated and resolved.

Open Access Statement: This is an Open Access article distributed in accordance with the Creative Commons Attribution-NonCommercial-NoDerivs 4.0 International 
License (CC BY-NC-ND 4.0), which permits the noncommercial replication and distribution of the article with the strict proviso that no changes or edits are made and the original work is properly cited (including links to both the formal publication through the relevant DOI and the license). See: https://creativecommons.org/licenses/by-nc-nd/4.0/.

\section{References}

1. Orsini E, Mireles-Cabodevila E, Ashton R, et al. How we do it: Lessons on outbreak preparedness from the Cleveland Clinic. Chest 2020;158:2090-6.

2. Mellnik T, Karklis L, Ba Tran A. Americans are delaying medical care, and its devastating health-care providers [Internet]. The Washington Post; 2020 Jun 2.

3. Landon E. Covid-19: What we know so far about the novel coronavirus [Internet]. University of Chicago Medicine; 2020 May 2.

4. Greenglass ER, Burke RJ. Stress and the effects of hospital restructuring in nurses. Can J Nurs Res 2001;33:93-108.

5. Hall H. The effect of the COVID-19 pandemic on healthcare workers' mental health. JAAPA 2020;33:45-8.

6. Blumenthal D, Fowler EJ, Abrams M, et al. Covid-19 Implications for the Health Care System. N Engl J Med 2020;383:1483-8.

7. King G. Crisis management \& team effectiveness: A closer examination. J Bus Ethics 2002;41:235-49.

8. Sommer SA, Howell JM, Hadley CN. Keeping positive and building strength: The role of affect and team leadership in developing resilience during an organizational crisis. GOM 2015;41:172-202.

9. Haslam SA. Making good theory practical: five lessons for an Applied Social Identity Approach to challenges of

doi: 10.21037/jhmhp-21-9

Cite this article as: Porter TH, Rathert C, Ayad S, Messina N. A One-Team approach to crisis management: a hospital success story during the COVID-19 pandemic. J Hosp Manag Health Policy 2021;5:18. organizational, health, and clinical psychology. Br J Soc Psychol 2014;53:1-20.

10. Paavola A. 12 hospitals laying off workers in response to Covid-19 [Internet]. Becker's Hospital CFO Report; 2020, July 2.

11. Kaplan M, Dollar B, Melian V, et al. Human capital trends 2016 survey [Internet]. Deloitte University Press; 2016.

12. Cross R, Rebele R, Grant A. Collaborative overload. Harv Bus 2016;94:74-9.

13. Stagl KC, Burke CS, Salas E, et al. Team adaptation: Realizing team synergy. In: Understanding adaptability: A prerequisite for effective performance within complex environments. Bingley: Emerald Group Publishing Limited; 2006:117-41.

14. Marks MA, Mathieu JE, Zaccaro SJ. A temporally based framework and taxonomy of team processes. Acad Manage Rev 2001;26:356-76.

15. Gilley JW, Gilley AM. The manager as coach. Westport, CT: Greenwood Publishing Group; 2007.

16. Lacerenza CN, Marlow SL, Tannenbaum SI, et al. Team development interventions: Evidence-based approaches for improving teamwork. Am Psychol 2018;73:517-31.

17. Tajfel H. Individuals and groups in social psychology. Br J Soc Clin Psychol 1979;18:183-90.

18. Turner JC, Hogg MA, Oakes PJ, et al. Rediscovering the social group: A self-categorization theory. Oxford: Basil Blackwell; 1987.

19. van Dick R, Wagner U, Stellmacher J, et al. Category salience and organizational identification. J Occup Organ Psychol 2005;78:273-85.

20. Blader SL, Tyler TR. A four-component model of procedural justice: defining the meaning of a "fair" process. Pers Soc Psychol Bull 2003;29:747-58. 